\title{
STRATEGI KOMUNIKASI PENGANUT AGAMA BAHA'I DALAM MEMBANGUN CITRA POSITIF DI MASYARAKAT
}

\author{
Illi Apriliyadi \\ Magister Ilmu Komunikasi FISIP Universitas Diponegoro, Semarang Indonesia \\ Illi.apriliyadi@gmail.com
}

Received: 28-05-2020 Revised: 14-06-2020 Accepted: 23-06-2020

\section{Communication Strategy Of Baha'i Religioners to Building Positive Images In The Community}

\begin{abstract}
;
Negative images are often experienced by co culture groups in the community, as experienced by Baha'i religious followers. Therefore they need a communication strategy in building a positive image in the community. This study aims to determine the communication strategies of Baba'i followers in the village of Cebolek. Kidul, Margoyoso sub-district, Pati regency in building a positive image in the community. This study examines the components of communication strategies in terms of message planning, communication approaches, and media selection. This research uses the co-culture theory by Mark. Orbe. The interpretative phenomenological analysis used in this study as analytical techniques of the data. The Result of this study show that Baba'i followers uses an Accommodation strategy to build a positive image in the community. This strategy ranges on the Non-Assertive Accommodation and the Assertive Accommodation. In the aspect of planning the message, the Baba'i Pati held a meeting with members of the local spiritual assembly before the message is delivered to the community. The communication approach is carried out by way of friendship with residents and local government officials, using verbal and non-verbal language by showing smiles and polite language. Finally in the aspect of media selection, Baha'is in the village of Cebolek use brochures and film screenings on Baha'is, this is done so that the public understands and knows about the teachings of the Baha'i faiths.
\end{abstract}

Keywords: Communication of Strategy, Baha'i Followers, Positive Image, Accomodation, Co Culture.

\begin{abstract}
Abstrak
Image (citra) negatif sering dialami oleh kelompok minoritas di lingkungan masyarakat, seperti yang dialami oleh penganut agama Baha'i. Oleh karena itu diperlukan strategi komunikasi dalam membangun citra positif di masyarakat. Penelitian ini bertujuan untuk mengetahui strategi komunikasi penganut agama Baha’i di desa Cebolek Kidul, kecamatan Margoyoso, kabupaten Pati dalam membangun citra positif di masyarakat. Penelitian ini mengkaji komponen strategi komunikasi dalam hal perencanaan pesan, pendekatan komunikasi, dan pemilihan media. Penelitian ini menggunakan teori budaya pendamping (co-culture theory) oleh Mark Orbe. Analisis fenomenologis interpretatif digunakan dalam penelitian ini sebagai teknik analisis data. Hasil penelitian ini menunjukkan bahwa umat Baha'i di desa Cebolek menggunakan strategi akomodasi untuk membangun citra positif di masyarakat. Strategi ini berkisar pada Akomodasi Non-Asertif dan Akomodasi Asertif. Dalam aspek perencaan pesan, umat Baha'i Pati melakukan musyawarah dengan anggota majelis rohani setempat sebelum pesan tersebut disampaikan kepada masyarakat. Pendekatan komunikasi dilakukan dengan cara
\end{abstract}


bersilaturahim dengan warga dan pejabat pemerintah setempat, menggunakan bahasa verbal dan non verbal yaitu dengan memperlihatkan senyuman dan bahasa yang sopan. Terakhir dalam aspek pemilihan media, umat Baha'i di desa Cebolek menggunakan brosur dan pemutaran film tentang Baha'i, hal ini dilakukan agar masyarakat memahami dan mengetahui tentang ajaran agama Baha'i

Kata kunci: Strategi Komunikasi, Penganut Agama Baha’i, Citra Positif, Akomodasi, Co Culture

\section{PENDAHULUAN}

Indonesia memiliki enam agama yang diakui secara sah oleh pemerintah dan dianut oleh sebagian besar masyarakat Indonesia yaitu Islam, Kristen, Katolik, Hindu, Budha, dan Konghucu. Selain agama-agama yang sah tersebut ada pula satu agama baru yang dianut oleh beberapa masyarakat Indonesia namun belum dikenal luas yaitu agama Baha’i. Agama Baha’i merupakan salah satu agama dengan jumlah penganut tidak sebanyak agama-agama besar, akan tetapi kehadiran agama Baha'i sesungguhnya diakui sebagai masyarakat agama. ${ }^{1}$ Agama Baha'i adalah agama yang independen dan bersifat universal, bukan sekte dari agama lain. Agama ini memiliki tujuan, mewujudkan tranformasi rohani dalam kehidupan manusia dan memperbaharui lembaga-lembaga masyarakat berdasarkan prinsip keesaan Tuhan, kesatuan agama-agama, dan kesatuan umat manusia. ${ }^{23}$ Agama Baha'i bukanlah agama missioner, mereka tidak mencari pengikut, tetapi jika ada yang ingin masuk ke dalam agama mereka, mereka sangat menerima dan terbuka ${ }^{4}$.

Seseorang yang ingin menjadi pemeluk Agama Baha’i tetapi telah memiliki agama sebelumnya diperbolehkan untuk masuk ke agama Baha'i tanpa meninggalkan agama sebelumnya. Hal ini dikarenakan umat Baha'i menjunjung tinggi arti persatuan dan kesatuan dalam kehidupan umat beragama di seluruh dunia. ${ }^{5}$ Implikasi daripada keterbukaan agama Bahai dalam prinsip kesatuan agama ini menjadikan agama Bahai sebagai agama kedua paling pesat berkembang setelah kristiani. ${ }^{6}$

\footnotetext{
${ }^{1}$ Siti Nadroh dan Syaiful Azmi, Agama-agama Minor (Jakarta: Kencana, 2015), 1.

${ }^{2}$ Agama Baha’i: hasil telaab kasus (Puslitbang, 1985).

${ }^{3}$ Agama Baha'i, 2017. Majelis Rohani Nasional Agama Baha'i, halaman 2

4 Nur Achmad dan Nucholis Madjid, Pluralitas agama: kerukunan dalam keragaman (Kompas Media Nusantara, 2001); Ananda Ulul Albab, "Interpretasi Dialog Antar Agama Dalam Berbagai Prespektif," Al-Mada: Jurnal Agama, Sosial, Dan Budaya 2, no. 1 (14 Februari 2019): 22-34, https://doi.org/10.31538/almada.v2i1.223; Dewi Haneh Amisani, "Konsep kepemimpinan dalam agama baha'i dan persepsinya terhadap pola kepemimpinan negara di Indonesia," 23 Desember http:/ / repository.uinjkt.ac.id/dspace/handle/123456789/27696.

5 Samsul Hidayat, "Stereotip Mahasiswa IAIN Pontianak Terhadap Agama Baha'i," Religió: Jurnal Studi Agama-Agama 7, no. 1 (20 Maret 2017): 55-83, https://doi.org/10.15642/religio.v7i1.703.

${ }^{6}$ Nurhanisah Senin dan Khadijah Mohd Khambali, "Islamic View on the Concept of Unity of Religion In,” International Journal of Humanities, Philosophy, Language 1, no. 4 (2018): 1.
} 
Illi Apriliyadi

Agama Baha'i masuk Indonesia dibawa oleh dua orang misionaris dari Iran yaitu Jamal Efendi dan Mustafa Rumi. ${ }^{7}$ Mereka mengadakan perjalanan keliling ke India, Burma (Myanmar), Singapura, dan Indonesia. Sepanjang perjalanan, kedatangan mereka selalu disambut dengan baik oleh para pembesar di setiap daerah yang mereka kunjungi. Mereka tiba di Batavia pada tahun 1878. ${ }^{8}$ Dari Batavia mereka berkunjung ke Surabaya dan Bali, kemudian lanjut perjalanan ke Makassar. Setelah itu agama Baha’i tersebar di beberapa daerah di Indonesia, salah satunya di Jawa Tengah. ${ }^{9}$

Penganut agama Baha’i terbanyak di Jawa Tengah terdapat di desa Cebolek, kecamatan Margoyoso, Pati. Warga desa Cebolek sendiri mayoritas merupakan pemeluk agama Islam. Berdasarkan wawancara ketika observasi awal, data penganut agama Baha’i di desa tersebut sebanyak 23 orang, 9 KK. Secara profesi penganut agama Baha’i di Cebolek bekerja sebagai guru, PNS, petani dan karyawan swasta ${ }^{10}$. Baha'i berada di posisi kedua sebagai jumlah penganut paling banyak setelah Islam.

Secara sosiologis agama Baha’i sudah cukup eksis di Desa Cebolek, Kecamatan Margoyoso, Kabupaten Pati walaupun kurang berkembang. Status agama Baha'i yang belum sah menjadi agama resmi negara Indonesia membuat warga di desa Cebolek memandang dengan sebelah mata. Sehingga stereotipe agama Baha’i di masyarakat tidak terlepas dari image negative bahkan dikatakan sebagai aliran sesat. ${ }^{11}$ Oleh karena dinilai memiliki image negative membuat umat Baha'i mendapatkan perlakuan diskriminatif dalam hal pelayanan hak sipil seperti pengosongan kolom agama diberi tanda setrip (-) di KTP. ${ }^{12}$ Dampak dari pengosongan kolom agama yang diterima oleh umat Baha'i di desa Cebolek sampai pada saat ini adalah tidak dikeluarkannya akta nikah oleh negara melalui Dinas Kependudukan dan Pencatatan

\footnotetext{
7 Jelle de Vries, "Jamal Effendi and Sayyid Mustafa Rumi in Celebes: The Context of Early Baha'i Missionary Activity in Indonesia," Baba’i Studies Review 14, no. 1 (1 Desember 2007): 23-37, https://doi.org/10.1386/bsr.14.23_1.

${ }^{8}$ Munawir Haris, "Pencarian Otentisitas Diri Komunitas Mu'allaf Di Kabupaten Sorong Papua Barat," Al-Qalam 20, no. 2 (9 Januari 2016): 329, https://doi.org/10.31969/alq.v20i2.192.

${ }^{9}$ Nuhrison M. Nuh, Makalah Seminar Penelitian Eksistensi Agama Baha'i Di Beberapa Daerah Di Indonesia (Studi Kasus di Pati (Jateng), Banyuwangi/Malang (Jatim), Palopo (Sulsel) dan Bandung (Jabar), yang diadakan oleh Puslitbang Kehidupan Keagamaan Badan Litbang dan Diklat, Kementerian Agama RI, pada tanggal 22 September 2014 di hotel Millenium Jakarta, halaman 9-13

${ }^{10}$ Wawancara dengan Penganut Agama Bahai, Maret 2020.

11 Moh Rosyid, "Resolusi Konflik Umat Agama Baha’i Dengan Muslim: Studi Kasus Di Pati Jawa Tengah,” Harmoni 18, no. 1 (30 Juni 2019): 424-42, https://doi.org/10.32488/harmoni.v18i1.345.

${ }_{12}$ Moh Rosyid, "Memotret Agama Baha'i Di Jawa Tengah Di Tengah Lemahnya Perlindungan Pemda," IIDYA SAMHITA: Jurnal Penelitian Agama 2, no. 2 (8 Desember 2017), http://ejournal.ihdn.ac.id/index.php/vs/article/view/170.
} 
Sipil Kabupaten Pati. ${ }^{13}$ Selain bermasalah dalam kolom agama di KTP dan akta nikah, umat Baha'i juga bermasalah dalam hal pencatatan status anak hasil pernikahan secara agama Baha’i di Kartu Keluarga $(\mathrm{KK}){ }^{14}$ Umat Baha’i juga pernah mengalami penolakan dalam hal pemakaman "Iya pada tahun 2010 salah satu anggota kami ada yang meninggal dunia (Bapak Hadi Sunarto) dan tidak diperbolehkan dimakamkan di makam umum bersama umat muslim." ${ }^{, 15}$ Namun akhirnya kepala desa Cebolek memberikan lahan untuk pemakaman umat Baha'i. Pada awalnya umat Baha’i tidak setuju dan menolak lahan yang diberikan kepala desa untuk dijadikan makam karena letaknya terlalu jauh dan tidak layak.

Meskipun umat Baha’i di desa Cebolek masih merasa terdiskriminasi dalam aspek pelayanan publik khususnya hak-hak sipil, namun umat Baha'i dan masyarakat setempat saat ini hidup berdampingan. Relasi sosial dengan masyarakat di sekitarnya, umumnya terjalin dengan baik karena mereka bertingkah laku yang sopan, santun dalam berbicara, dan aktif dalam setiap kegiatan ke-RT-an. ${ }^{16}$ Masyarakat menilai penganut agama Baha’i cukup terbuka untuk ukuran kelompok minoritas dan penganut agama Baha'i memiliki sikap yang baik. ${ }^{17}$ Sementara itu, komunikasi sosial penganut Baha’i terhadap masyarakat di sekitarnya adalah dengan mengundang para tetangga yang berlainan keyakinan dalam perayaan agama Baha’i seperti Ridwan dan NawRuz. ${ }^{18}$ Image (Citra) negatif yang dialami oleh umat Baha’i disebabkan oleh ketidaktahuan masyarakat tentang agama Baha’i. Maka dari itu penganut agama Baha’i berusaha untuk melakukan strategi komunikasi dalam membangun citra positif di masyarakat.

Penelitian ini bertujuan untuk mengetahui strategi komunikasi penganut agama Baha’i di desa Cebolek Kidul, kecamatan Margoyoso, kabupaten Pati dalam membangun citra positif di masyarakat berdasarkan Teori Budaya Pendamping (Co-Cultural Theory) dengan menekankan pada aspek perencanaan pesan, pemilihan media dan pendekatan komunikasi.

${ }^{13}$ Moh Rosyid, "Potret Perkawinan Umat Agama Baha’i Dengan Uu Nomor 1 Tahun 1974: Studi Kasus Di Pati Jawa Tengah," YUDISIA: Jurnal Pemikiran Hukum Dan Hukum Islam 7, no. 2 (2016): 435-69, https://doi.org/10.21043/yudisia.v7i2.2163.

14 Anna Kostantia Panjaitan, "Implikasi Pengosongan Kolom Agama Dalam Kartu Tanda Penduduk Terhadap Pemenuhan Hak Konstitusional Umat Baha'i," Indonesian State Law Review (ISLRev) 1, no. 1 (1 November 2018): 1-16, https://doi.org/10.15294/islrev.v1i1.26936.

${ }^{15}$ Wawancara \& Observasi pada tgl 19-20 Maret 2020

${ }^{16}$ Nuhrison M. Nuh, "Analisis Kebijakan Pemerintah terhadap Penganut Agama Baha'i di Kabupaten Pati, Provinsi Jawa Tengah,” Harmoni 14, no. 3 (2015): 129.

17 Puji Hartatik dan LISTYANINGSIH, "Persepsi Masyarakat terhadap Kelompok Penganut Agama Bahai di Desa Cebolek Kidul Kecamatan Margoyoso Kabupaten Pati," Kajian Moral dan Kewarganegaraan 7, no. 2 (24 Juni 2019), https://jurnalmahasiswa.unesa.ac.id/index.php/jurnal-pendidikankewarganegaraa/article/view/28252.

18 Umi Rojiati, "Manajemen Komunikasi Sosial Penganut Agama Baha'i," Communicatus: Jurnal Ilmu Komunikasi 3, no. 1 (25 Juni 2019): 1-16, https://doi.org/10.15575/cjik.v3i1.5033. 
Illi Apriliyadi

\section{KAJIAN LITERATUR}

\section{Strategi Komunikasi}

Strategi komunikasi pada hakikatnya adalah perencanaan (planning) dan manajemen (management) untuk mencapai tujuan. ${ }^{19}$ Strategi komunikasi adalah tahapan konkret dalam rangkaian aktifitas komunikasi yang berbasis pada satuan teknik bagi pengimplemintasian tujuan komuniasi, adapun teknik adalah satu pilihan tindakan komunikasi tertentu berdasarkan strategi yang telah ditetapkan sebelumnya. ${ }^{20}$ Sementara itu seorang pakar perencanaan komunikasi Middleton ${ }^{21}$ membuat definisi dengan menyatakan "strategi komunikasi adalah kombinasi terbaik dari semua elemen komunikasi mulai dari komunikator, pesan, saluran (media), penerima sampai pada pengaruh (efek) yang dirancang untuk mencapai tujuan komunikasi yang optimal."2223

Dalam merumuskan strategi komunikasi selain diperlukan perumusan tujuan yang jelas, juga memperhitungkan kondisi dan situasi khalayak atau sasaran. ${ }^{24} \mathrm{R}$. Wayne Pace, Brent D.Paterson, dan M.Dallas Burnet dalam bukunya, Techniques for Effective Communication $^{25}$, menyatakan bahwa tujuan sentral dari strategi komunikasi terdiri atas tiga yaitu pertama to secure artinya memastikan bahwa komunikan mengerti dengan pesan yang diterimanya. Kedua ketika komunikan telah mengerti dan menerima, penerimanya itu harus dibina (to establish acceptance) dan yang terakhir kegiatan komunikasi harus dimotivasikan (tomotivate action). ${ }^{26}$

Beberapa komponen yang harus di perhatikan dalam melakukan strategi komunikasi, yaitu:

Perencanaan Pesan: Perencanaan pesan yang baik dapat membuat pesan diterima baik oleh komunikan sehingga dapat memberikan feedback atas pesan yang disampaikan oleh komunikator kepada komunikan ${ }^{27}$. Pendekatan Komunikasi: Pendekatan komunikasi dapat dilakukan oleh komunikator dengan memberikan informasi yang tepat sehingga komunikan mengetahui informasi yang berada di lingkungan sekitar dan tidak salah dalam menilai karakter

\footnotetext{
${ }^{19}$ Onong Uchjana Effendy, Ilmu komunikasi: teori dan praktek (PT Remaja Rosdakarya, 2011), 30.

${ }^{20}$ Effendy, 32.

${ }^{21}$ Yrjo Engeström dan David Middleton, Cognition and Communication at Work (Cambridge University Press, 1998), 31.

${ }^{22}$ Alo Liliweri, Strategi Komunikasi Masyarakat (Lkis Pelangi Aksara, 2010).

${ }^{23}$ Cangara Hafied, Perencanaan Dan Strategi Komunikasi. (Jakarta: Raja Grafindo Persada, 2014), 65.

${ }_{24}^{24}$ Anwar Arifin, Strategi komunikasi sebuah pengantar ringkas (Bandung: Armico, 1982), 59.

${ }^{25}$ R. Wayne Pace, Brent D. Peterson, dan M. Dallas Burnett, Techniques for Effective Communication (Addison-Wesley, 1979), 4.

${ }_{27}^{26}$ Arifin, Strategi komunikasi sebuah pengantar ringkas, 16.

${ }^{27}$ A. Lukman Hakim, "Strategi Komunikasi Lintas Agama FKUB Surabaya Dalam Menangani Konflik," Al-Mada: Jurnal Agama, Sosial, Dan Budaya 1, no. 1 (5 Januari 2018): 19-34, https://doi.org/10.31538/almada.v1i1.129.
} 
seseorang. Pemilihan Media: Pemilihan media diperlukan oleh seorang komunikator sehingga komunikator dalam menggunakan media harus memberikan pemahaman yang tepat agar komunikan mengetahui isi pesan yang sebenarnya dan sesuai dengan kenyataannya ${ }^{28}$.

Menurut Ruslan, menyatakan, agar suatu strategi dapat efektif dalam mencapai tujuannya, maka ia harus mencakup beberapa hal ${ }^{29}$ :

Objektif, jelas dan menentukan semua ikhtiar diarahkan untuk mencapai pemahaman yang jelas, menentukan dan dapat mencapai keseluruhan tujuan. Tujuan tersebut tidak perlu dibuat secara tertulis namun yang penting dapat dipahami dan menentukan.

Memelihara inisiatif. Strategi inisiatif menjaga kebebasan bertindak dan memperkaya komitmen. Strategi mesti menentukan langkah dan menetapkan tindakan terhadap peristiwa, bukannya bereaksi terhadap satu peristiwa.

Konsentrasi, dengan memusatkan kekuatan yang besar untuk waktu dan tempat yang menentukan.

Fleksibilitas, strategi hendaknya diniatkan untuk dilengkapi penyangga dan dimensi untuk fleksibilitas dan maneuver.

\section{Citra}

Image (citra) organisasi, lembaga ataupun komunitas menjadi salah satu pegangan bagi setiap anggota dalam mengambil keputusan penting. Image (citra) yang baik akan menimbulkan dampak positif bagi organisasi/lembaga, sedangkan image (citra) yang buruk melahirkan dampak negatif dan melemahkan kemampuan organisasi/lembaga dalam persaingan ${ }^{30}$.

Menurut Keith Davis ${ }^{31}$ dalam bahasa komuniksai, citra adalah The picture in ourhead (gambar yang ada dalam kepala kita). Gambar ini dimaksudkan adalah gambar mental yang mengandung unsur positif dan negatif. ${ }^{3233}$ Selain itu pengertian citra menurut Kasali adalah "kesan yang timbul karena pemahaman akan suatu kenyataan, pemahaman itu sendiri muncul

\footnotetext{
${ }^{28}$ Effendy, Ilmu komunikasi, 33.

${ }^{29}$ Rosady Ruslan, Manajemen bumas dan manajemen komunikasi: konsepsi dan aplikasi, Revisi (Jakarta: PT Raja Grafindo Persada, 2002), 41.

${ }^{30}$ Alem Joko Pamungkas dan Hasta Mardi Setiawan, "Strategi Public Relations Dalam Membangun Citra Positif (studi Empiris Pada Pondok Pesantren Modern Darul Amanah Sukorejo Kabupaten Kendal)," Jurnal Egaliter 2, no. 03 (2018).

${ }^{31}$ Keith Davis, Management Communication and the Grapevine (Graduate School of Business Administration, Harvard University, 1953).

${ }^{32}$ Robert L. Heath dan W. Timothy Coombs, Today's Public Relations: An Introduction (SAGE, 2006).

${ }^{33}$ Yulianita, N. 2005. Dasar-Dasar Public Relations. Bandung: Fakultas Ilmu Komunikasi Universitas Islam Bandung. 47
} 
Illi Apriliyadi

karena adanya informasi". ${ }^{34}$ Citra pada dasarnya merupakan tujuan pokok dalam suatu organisasi maupun kelompok, pengertian citra sendiri abstrak atau intangible, tetapi wujudnya dapat dirasakan dari penilaian, baik semacam tanda respect (rasa hormat) dari publik sekelilingnya atau masyarakat luas terhadap organisasi atau kelompok tersebut.

\section{Teori Budaya Pendamping (Co-Cultural Theory)}

Teori Budaya Pendamping (Co-Cultural Theory) berasal dari serangkaian kajian terhadap bagaimana anggota kelompok terwakilkan (Co Culture, minoritas) seperti komunitas gay, lesbian, biseksual, transgender, wanita atau para difabel berkomunikasi dengan anggota budaya dominan atau mayoritas. Co-Cultural Theory berusaha menjelaskan bagaimana orang orang dalam kelompok co culture memilih strategi yang berbeda untuk menghilangkan/melewati stereotip, bekerja membangun hubungan dengan kelompok dominan atau bahkan menghindari kelompok dominan. ${ }^{35}$

Co-Cultural Theory menjelaskan bahwa anggota budaya pendamping (Co Cultural Group) memiliki tiga kemungkinan tujuan strategi komunikasi ketika berinteraksi dengan para anggota kelompok dominan (masyarakat). Pertama adalah asimilasi dengan menjadi bagian dari kultur dominan. Kedua, melakukan akomudasi, yaitu berusaha agar para anggota kelompok dominan dapat menerima para anggota Co-Cultural. Lalu yang terakhir memilih untuk menolak kemungkinan ikatan bersama dengan para anggota kelompok dominan atau separasi. ${ }^{36}$

Orbe manambahkan, terdapat tiga pendekatan yang dilakukan co cultural group dalam interaksi mereka dengan kelompok budaya dominan. Pertama dengan pendekatan non-assertive dengan asumsi pendekatan komunikasi yang dilakukan mengedepankan kebutuhan orang lain, bersifat non-konfrontatif dan cenderung memperlambat komunikasi. Kedua, melakukan pendekatan assertive. Artinya, kelompok budaya pendamping (co cultural group) berkomunikasi dengan ekspresif dengan memperhitungkan kepentingan diri sendiri dan orang lain. Terakhir melalui pendekatan agresif dimana kelompok co cultural secara gamblang mempromosikan diri meski terkadang merampas kepentingan orang lain orang lain. ${ }^{3738}$

\footnotetext{
${ }^{35}$ Stephen W. Littlejohn dan Karen A. Foss, Theories of Human Communication: Tenth Edition (Waveland Press, 2010), 264.

${ }^{36}$ Ibid hlm 265

37 Mark P. Orbe dan Tabatha L. Roberts, "Co-Cultural Theorizing: Foundations, Applications \& Extensions," Howard Journal of Communications 23, no. 4 (1 Oktober 2012): 293-311, https://doi.org/10.1080/10646175.2012.722838.

38 Chand, Daniel. 2014. Mark Orbe's Co-Cultural Theory. Journal of Communication. Illinois State University Volume 37.372
} 1994), 30.

${ }^{34}$ Rhenald Kasali, Manajemen public relations: konsep dan aplikasinya di Indonesia (Pustaka Utama Grafiti, 


\section{METODE PENELITIAN}

Penelitian ini merupakan penelitian kualitatif, dimana peneliti meneliti permasalahan secara mendalam dan mencari informasi sebanyak mungkin dengan metode pengumpulan data yang terdapat dalam penelitian kualitatif. Permasalahan yang akan dikaji oleh peneliti merupakan masalah yang bersifat sosial dan dinamis. Oleh karena itu, peneliti memilih menggunakan metode penelitian kualitatif untuk menentukan prosedur mencari, mengumpulkan, mengolah dan menganalisis data hasil penelitian tersebut. ${ }^{39}$

Penelitian ini menggunakan pendekatan fenomenologi. Fenomenologi adalah ilmu tentang hakikat dan bersifat a priori. Hurssel juga mengatakan fenomenologi dapat mempelajari bentuk-bentuk pengalaman dari sudut pandang orang yang mengalaminya secara langsung, seolah-olah kita mengalaminya sendiri ${ }^{40}$. Fenomenologi tidak hannya mengklasifikasikan setiap tindakan sadar yang dilakukan, namun juga meliputi prediksi terhadap tindakan di masa yang akan datang. ${ }^{41}$

Pada penelitian ini, pengumpulan data dilakukan dengan cara observasi secara langsung (participant observation), wawancara (interview) dan dokumentasi terhadap informan yang menjadi subjek penelitian. Informan atau subjek dalam penelitian ini adalah pengurus inti Majelis Rohani Setempat (MRS) agama Baha'i di desa Cebolek, kecamatan Margoyoso, Pati yang dipilih dengan memperhatikan secara jeli aspek field of experiences (pengalaman), life history (sejarah hidup), life goals (pandangan terhadap kehidupan), dan situational context (konteks situasi). Data dari para pengurus MRS Baha'i Pati semacam ini sangat penting bagi perkembangan studi-studi berbasis Co-Cultural.

\section{Analisa Data}

Dalam penelitian ini proses analisis data mengacu pada Interpretative Phenomenological Analysis (IPA) sebagaimana ditulis oleh Jonathan A. Smith. Analisis ini bertujuan untuk mengungkap secara detail bagaimana partisipan memaknai dunia ersonal dan sosialnya. ${ }^{42}$ Tahap-tahap IPA yaitu:

1. Reading and re-reading,

2. Initial noting,

3. Developing Emergent Themes,

\footnotetext{
${ }^{39}$ Moloeng Lexy J, Metodologi penelitian Kualitatif, 29 ed. (Bandung: Rosdakarya, 2011), 7.

${ }^{40}$ Clark E. Moustakas, Phenomenological Research Methods, 6. print. (Thousand Oaks, Calif.: Sage Publ, 1999).

${ }^{41}$ Kuswarno Engkus, Metodelogi Penelitian Komunikasi, Fenomenologi, Konsepsi dan Pedoman (Bandung: Widya Padjadjaran, 2009).

${ }^{42}$ Jonathan A. Smith, Paul Flowers, dan Michael Larkin, Interpretative Phenomenological Analysis: Theory, Method and Research (SAGE, 2009).
} 
Illi Apriliyadi

4. Searching for connections across emergent themes,

5. Moving the next cases.,

6. Looking for patterns across cases.

Setelah tahap-tahap IPA dilakukan, maka yang akan dilakukan adalah membawanya ke bagian selanjutnya yaitu melakukan interpretasi data hasil analisis yang akan dituliskan pada bagian temuan dan pembahasan. ${ }^{43}$

\section{TEMUAN DATA DAN PEMBAHASAN}

\section{Strategi Komunikasi Penganut Agama Baha'i Dalam Membangun Citra Positif di}

\section{Masyarakat}

Menurut Effendy ${ }^{44}$ komponen yang harus diperhatikan dalam melakukan strategi komunikasi yaitu perencanaan pesan, pendekatan komunikasi, dan pemilihan media. Informan penelitian yang diwawancara dalam penelitian ini adalah pengurus inti Majelis Rohani Setempat (MRS) Agama Baha’i di desa Cebolek, kecamatan Margoyoso, kabupaten Pati yang berjumlah empat orang, dan satu anggota yaitu:

Tabel. 1: Pengurus Majelis Rohani Setempat (MRS) Baha'i Pati

\begin{tabular}{lll}
\hline Nama & Jabatan & Pekerjaan/Profesi \\
\hline Bpk. Andhika H.W & Ketua & Guru \\
Bpk. Sanusi & Wakil ketua & Pensiunan PNS \\
Bpk.Hujjat R & Sekretaris & PNS \\
Ibu Sulistiyani & Bendahara & Guru \\
Ibu Sukarni & Anggota & Wiraswasta/Ibu rumah tangga \\
\hline
\end{tabular}

Sumber: Wawancara penulis dengan pengurus MRS Baha'i Pati

Hasil wawancara informan tersebut diatas dirangkum menjadi sebuah narasi untuk mempermudah dalam penulisan. Berikut adalah hasil wawancara peneliti dengan pengurus inti Majelis Rohani Setempat (MRS) komponen yang diperhatikan dalam strategi komunikasi yaitu: perencanaan pesan, pendekatan komunikasi, dan pemilihan media.

\section{Perencanaan Pesan}

Berdasarkan hasil wawancara, umat Baha'i di desa Cebolek melaksanakan musyawarah dengan pengurus Majelis Rohani Setempat (MRS) dalam merencanakan pesan sebelum pesan tersebut disampaikan kepada khalayak (masyarakat). Hal tersebut dilakukan sebagai sarana

\footnotetext{
${ }^{43}$ Igor Pietkiewicz dan Jonathan A. Smith, "A practical guide to using interpretative phenomenological analysis in qualitative research psychology," Psychological journal 20, no. 1 (2014): 7-14.

${ }^{44}$ Effendy, Ilmu komunikasi.
} 
untuk membuat keputusan dalam segala aspek kehidupan, baik dalam masalah-masalah pribadi maupun persoalan umum. Musyawarah dilakukan dalam menyusun kata-kata yang baik sehingga pesan yang disampaikan dapat diterima dan dipahami dengan baik oleh masyarakat.

Salah satu informan mengatakan, "Kami berpedoman pada institut buku 1 tentang materi percakapan bermakna dan buku-buku tentang bangkit untuk mengabdi dengan tujuan memotivasi semangat umat Baha’i dalam berbagi pesan kepada orang lain. Musyawarah yang kami lakukan diawali dengan berdo'a supaya mendapat petunjuk dalam perencanaan pesan, dan kerelaan Tuhan Yang Maha Esa." ${ }^{45}$

Gambar 1. Musyawarah umat Baha’i dengan pengurus Majelis Rohani Setempat (MRS) dengan perwakilan dari Majelis Rohani Nasional (MRN)

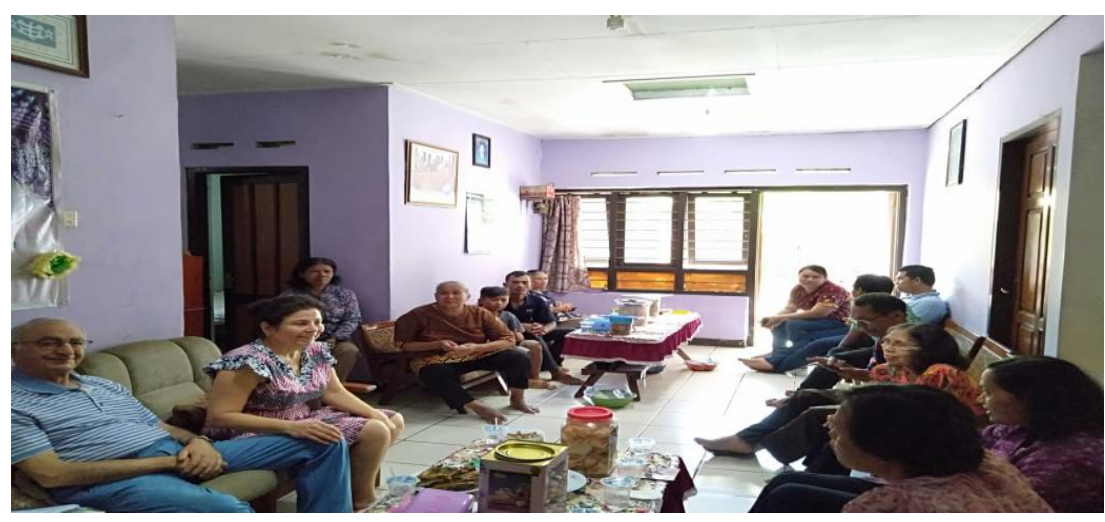

Sumber:: Koleksi dokumentasi pribadi MRS Pati

Perencanaan pesan dilakukan oleh umat Baha'i dengan cara musyawarah selain menyusun pesan yang akan disampaikan kepada khalayak juga mendorong pencarian kemungkinan-kemungkinan baru, membangun kesatuan dan kemufakatan, serta menjamin kesuksesan pelaksanaan keputusan kelompok. Hal tersebut dilakukan sesuai dengan ajaran Baha'ullah selaku pembawa agama Baha'i yaitu:

"Musyawarah menghasilkan kesadaran yang lebih dalam mengubah dugaan menjadi keyakinan. Musyawarah adalah laksana sebuah cahaya cemerlang, yang membimbing dan menunjukkan jalan di dalam dunia yang gelap. Dalam setiap hal, selalu dan selamanya memiliki suatu tingkat kesempurnaan dan kedewasaan. Tingkat kedewasaan dari berkah pengertian akan diwujudkan melalui musyawarah (Baha'ullah). ${ }^{46}$

\section{Pendekatan Komunikasi}

Pendekatan komunikasi dalam strategi sangat dibutuhkan supaya pesan yang akan disampaikan kepada masyarakat mudah untuk dipahami dan diterima dengan baik. Umat

\footnotetext{
${ }^{45}$ Sulistyani, Wawancara dengan Ibu Sulistyani, bendahara MRS Agama Baha’i Pati, 2020.

${ }^{46}$ Agama Baha’i (Majelis Rohani Nasional Agama Baha’i, 2017), 17.
} 
Illi Apriliyadi

Baha'i di desa Cebolek sebagai komunikator melakukan pendekatan komunikasi dengan cara bersilaturahim dengan masyarakat sekitar, menggunakan bahasa verbal dan non verbal serta selalu berusaha untuk bersikap terbuka dan tidak menutup diri. Sekretaris MRS Pati mengatakan bahwa "Kami melakukan pendekatan komunikasi dengan masyarakat dengan tidak membeda-bedakan latar belakang suku, agama, maupun pekerjaan. Kami selalu berusaha untuk menggunakan percakapan bermakna dengan berpenampilan yang sopan dan sewajarnya, memberikan senyuman, menggunakan bahasa yang sederhana, jelas dan tidak berbelit-belit serta tidak ada ciri khas pakaian yang digunakan." ${ }^{, 47}$.

Gambar 2. Silaturahim dan Do'a bersama warga setempat

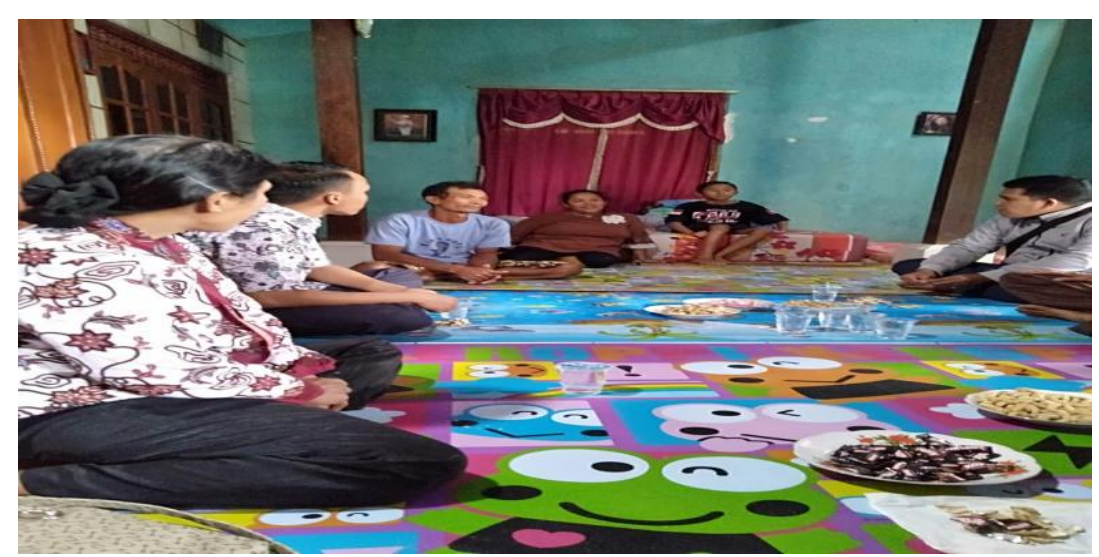

Sumber: Koleksi dokumentasi pribadi MRS Baha’i Pati

Sebagai komunikator, Umat Baha’i melakukan pendekatan komunikasi tersebut untuk menghilangkan segala bentuk prasangka baik ras, suku bangsa, agama, warna kulit, maupun jenis kelamin. Karena prasangka merupakan penghalang terbesar bagi terwujudnya suatu kehidupan yang damai dan harmonis di dalam suatu masyarakat yang beraneka ragam. ${ }^{48}$

\section{Pemilihan Media}

Media sangat berperan aktif dalam membantu proses penyampaian pesan agar dapat diterima oleh masyarakat sekitar. Umat Baha'i menggunakan media cetak seperti brosur dan media elektronik melalui pemutaran video tentang agama Baha’i ketika mengundang masyarakat sekitar dalam perayaan hari besar umat Baha'i seperti perayaan Ridwan dan Naw Ruz. " kami menggunakan brosur mengenai kegiatan yang kami lakukan, dan pemutaran video/film tentang agama Baha'i supaya hadirin (masyarakat) memahami tentang agama Baha'i." 49

\footnotetext{
${ }^{47}$ Wawancara dengan sdr Hujjat Ruhydin, sekretaris MRS Agama Baha'i Pati

${ }^{48}$ Wawancara dengan bapak Sanusi, Wakil ketua MRS Agama Baha’i Pati

${ }^{49}$ Wawancara dengan bapak Andhika, Ketua MRS Agama Baha'i Pati
} 
Pemilihan media tersebut bertujuan agar masyarakat mengetahui informasi tentang agama Baha’i. Sehingga umat Baha’i mendapatkan citra (image) yang baik di mata masyarakat.

Gambar. 3 Brosur Agama Baha'i yang diterbitkan oleh Majelis Rohani Nasional

(MRN) Baha'i Indonesia

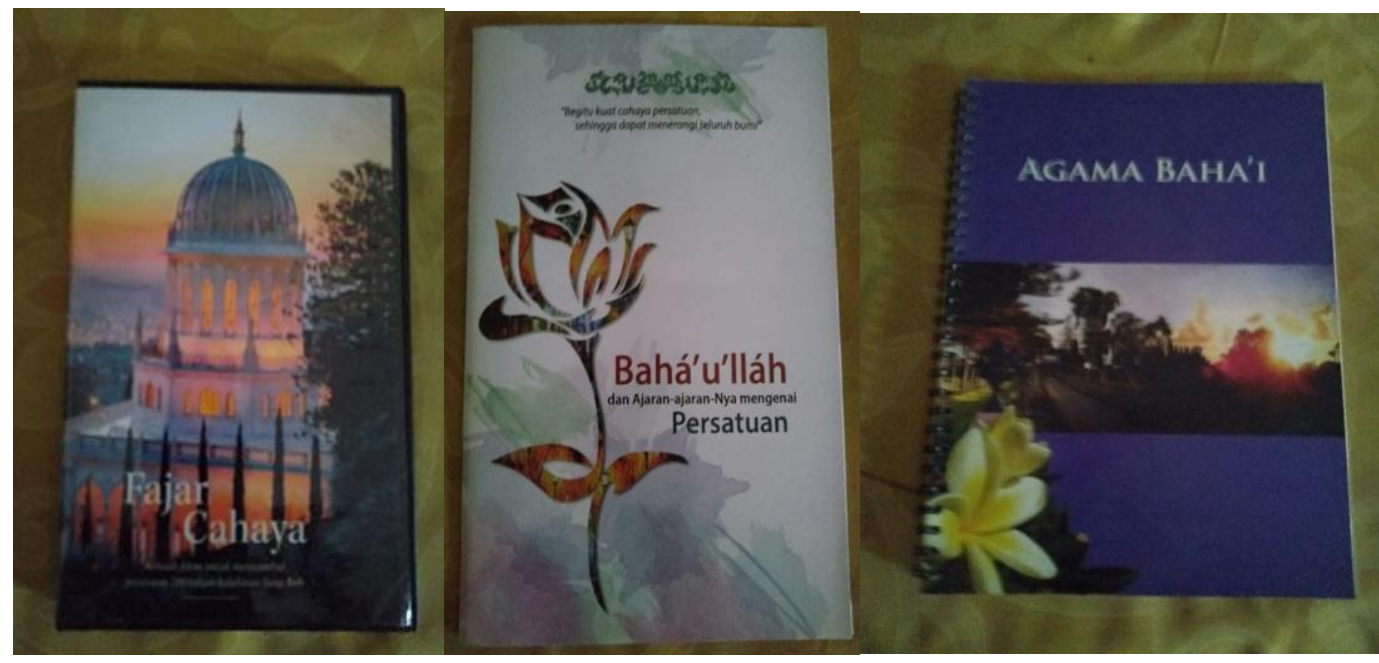

Sumber : Koleksi pribadi MRS Baha’i Pati

Tabel: 2. Analisa Data

\begin{tabular}{ll}
\hline Komponen Strategi Komunikasi & \multicolumn{1}{c}{ Keterangan } \\
\hline Perencanaan Pesan & Langkah-langkah yang dilakukan umat Baha'i dalam \\
& perencanaan Pesan yaitu: \\
& - Mengadakan musyawarah dengan anggota Majelis \\
& Rohani Setempat (MRS) Pati. \\
& - Mempelajari kembali Institut buku 1 tentang materi \\
& percakapan bermakna dan buku 2 tentang bangkit \\
& untuk mengabdi dengan tujuan memotivasi semangat \\
& umat Baha'i dalam berbagi dengan orang lain. \\
& - Setiap melakukan kegiatan diawali dengan berdo'a \\
& supaya mendapat petunjuk dan kerelaan Tuhan Yang \\
& Maha Esa. \\
& Diantara cara untuk memperkenalkan agama Baha'i \\
& yaitu mengadakan percakapan bermakna dengan \\
& berpenampilan yang sopan dan sewajarnya, \\
Pendekatan Komunikasi & memberikan senyuman dan ramah tamah kepada \\
& yang hadir, menggunakan bahasa yang sederhana, \\
& jelas dan tidak berbelit-belit, menanamkan sikap \\
& bijaksana sehingga tidak menyinggung perasaan yang \\
& hadir dan menghargai pendapat mereka. \\
a. Melalui media cetak yaitu brosur agama Baha'i
\end{tabular}


b. Melalui media elektronik yaitu dengan pemutaran video tentang agama Baha'i.

Sumber: Hasil wawancara penulis dengan narasumber pengurus MRS Baha’i Pati

\section{PEMBAHASAN}

\section{Strategi Komunikasi Penganut Agama Baha'i dalam Membangun Citra Positif di} Masyarakat berdasarkan Teori Budaya Pendamping (Co-Cultural Theory)

Peneliti melihat bahwa umat Baha’i di desa Cebolek menonjolkan diri sebagai masyarakat biasa pada umumnya, bukan sekedar dikenal melalui hal yang kasat mata saja atau dianggap aneh. Umat Baha'i selalu berusaha membangun hidup harmonis dengan masyarakat sekitar. Proses interaksi antara umat Baha'i dengan masyarakat sekitar berdasarkan hasil wawancara menunjukkan strategi akomodasi.

Sebagai kelompok co culture, umat Baha'i berusaha untuk menciptakan "pluralisme

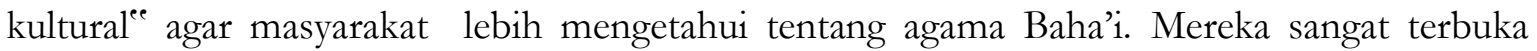
dalam memperkenalkan dan memberikan informasi mengenai ajaran agama Baha’i

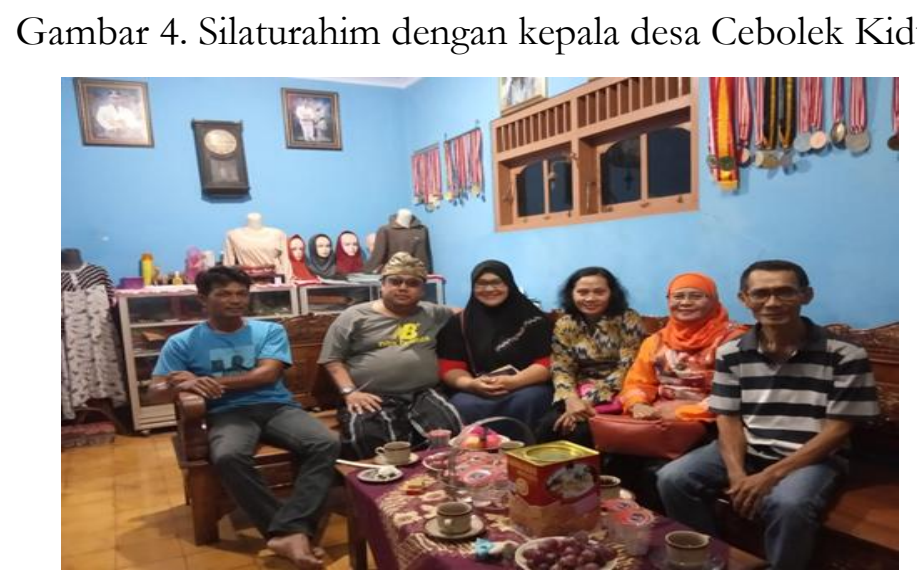

Sumber: Dokumentasi pribadi MRS Baha'i Pati

Selain itu dalam menghadapi struktur-struktur dominan yang opresif, umat Baha'i sebagai kelompok co culture menggunakan dialog sebagai cara untuk terciptanya relasi antara umat Baha'i dengan masyarakat setempat sebagai representasi dari masyarakat dominan. Dialog berguna untuk lebih memperkenalkan agama Baha'i dan juga membangun relasi komunikasi yang lebih intim antara umat Baha’i dengan masyarakat sekitar. Penerapan strategi akomodasi yang dilakukan oleh umat Baha'i di desa Cebolek merupakan bentuk usaha agar diterima dan membangun citra positif di lingkungan masyarakat. 
Gambar 5. Audiensi Umat Baha’i Pati dengan Depag Pati

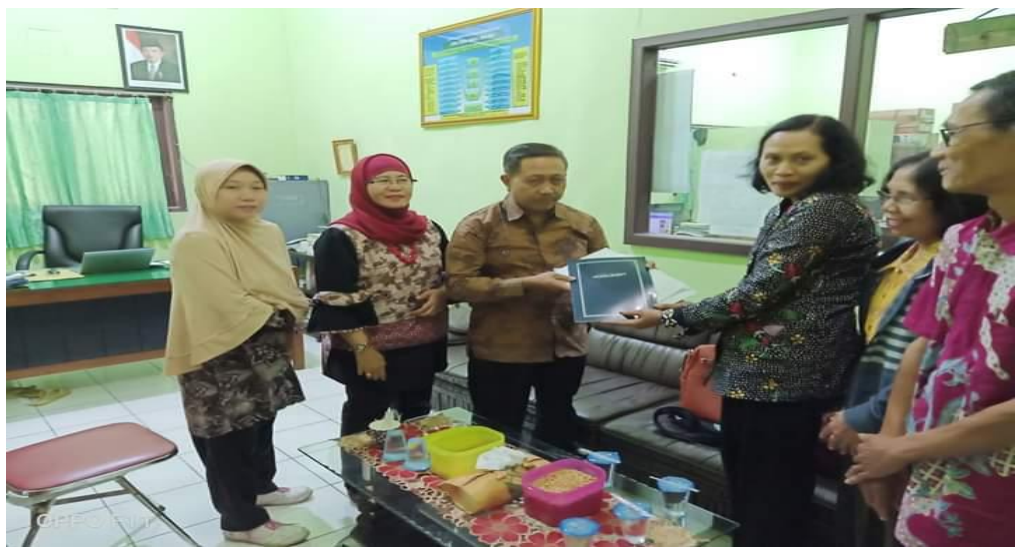

Sumber: Koleksi dokumentasi kegiatan MRS Baha’i Pati

Interaksi yang dilakukan oleh umat Baha'i dengan masyarakat setempat terbagi dalam dua fase. Fase pertama, merupakan fase menggunakan pendekatan non asertif. Pendekatan ini terlihat saat kelompok Baha'i sering mengundang perayaan hari-hari besar agama Baha'i kepada pejabat pemerintah setempat dan masyarakat sekitarnya. Seperti Perayaan Ayyami-Ha (Hari-Hari Sisipan), Perayaan Naw-ruz, Perayaan Ridwan dan Do'a bersama.

Gambar 6. Perayaan Dwi Abad Kelahiran Sang Bab bersama Masyarakat setempat dan dihadiri oleh Camat, Kapolsek, dan Danramil Kecamatan Margoyoso, Pati

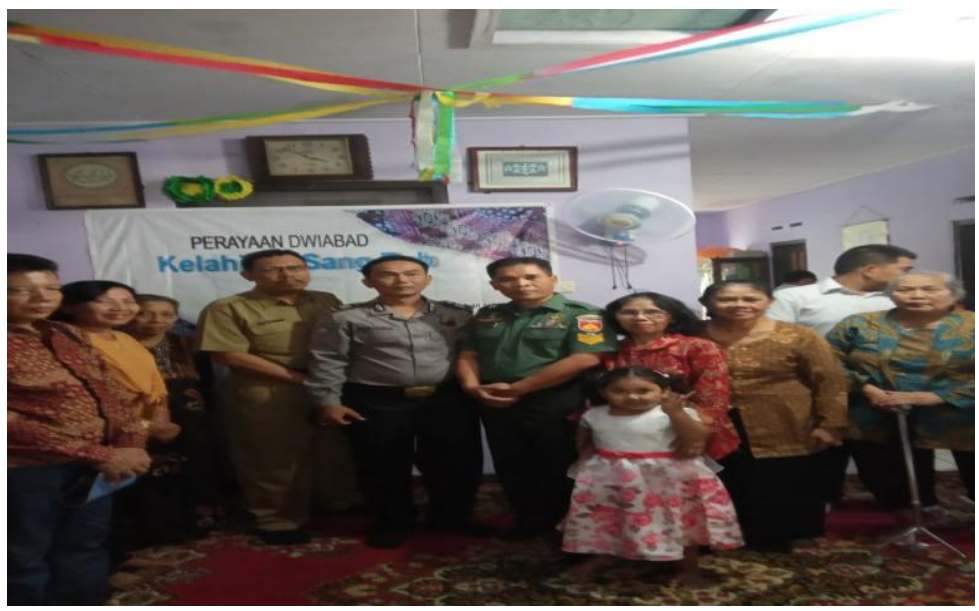

(Sumber: Koleksi dokumentasi kegiatan MRS Baha’i Pati)

Temuan penelitian tersebut menurut peneliti menggambarkan pendekatan non-asertif yaitu pendekatan yang tidak mengkonfrontasi secara langsung. Salah satu poin yang juga memperlihatkan pendekatan ini ada bagaimana kelompok co culture secara memperkenalkan dan memepertahankan kehadiran budayanya. ${ }^{50}$

${ }^{50}$ William B. Gudykunst, Theorizing about intercultural communication (Sage, 2005), 175. 
Illi Apriliyadi

Fase kedua, umat Baha’i menggunakan pendektakan asertif. Konklusi ini diperkuat oleh bagaimana interaksi antara umat Baha'i sebagai kelompok co culture dan masyarakat setempat tidak membatasi masing-masing pihak. Umat Baha'i berusaha untuk membaur dengan masyarakat setempat dan ikut berpartisipasi dalam kegiatan yang diadakan oleh desa Cebolek seperti do'a bersama lintas agama, berpartisipasi menyumbang dana untuk Mushola RT dan Masjid desa Cebolek, ikut gotong-royong dalam acara bersih desa Cebolek dam berpartisipasi dalam kepedulian dampak virus Corona (Covid-19) kepada warga Cebolek yang membutuhkan bantuan.

Gambar 7. Do’a Bersama Lintas Agama, Kepercayaan dan Tokoh Masyarakat)

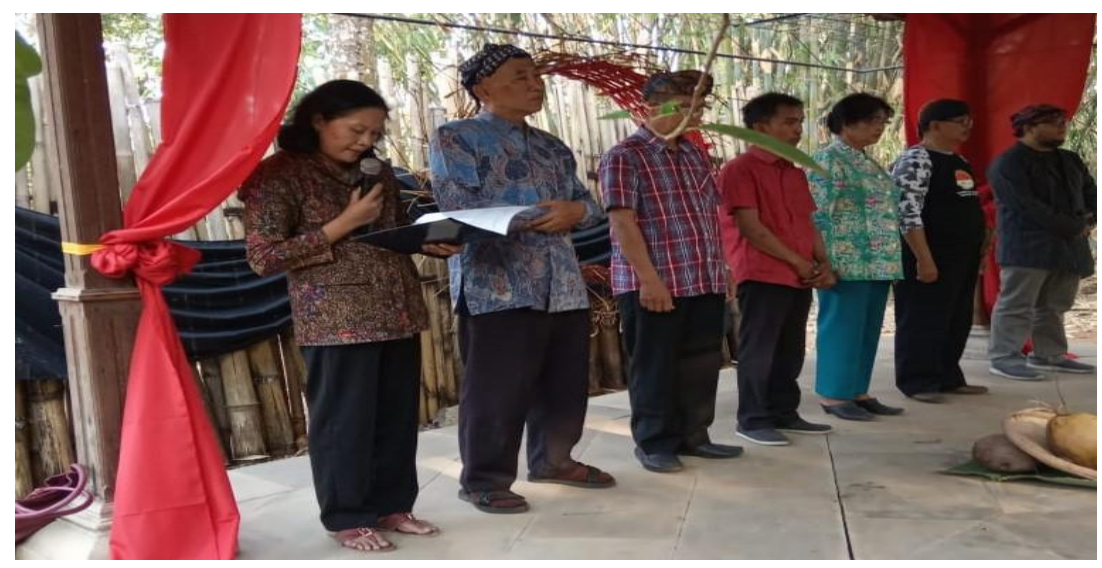

(Sumber: Koleksi dokumentasi kegiatan MRS Baha’i Pati)

Proses komunikasi dua arah ini menggambarkan asumsi pendekatan asertif yang disampaikan oleh Orbe yakni pendekatan yang mencakup self-enbacing (peningkatan diri) menggunakan komunikasi yang ekspresif namun dengan memperhitungkan kepentingan diri sendiri maupun orang lain.

\section{Orientasi Komunikasi}

Orientasi yang ditemukan dalam penelitian ini yaitu pertama, umat Baha’i menunjukkan orientasi komunikasi berupa non assertive accomodation. Fase pertama terlihat umat Baha'i dalam kehidupan sehari-hari dalam kehidupan masyarakat dengan menonjolkan diri seperti masyarakat biasa pada umumnya. Tidak ada ciri khas dalam berpakaian maupun bahasa yang digunakan. Non asertive accomodation ini terlihat dalam bagaimana umat Baha’i menekankan commonalities, memperkenalkan dan mendapatkan posisi ditengah masyarakat dominan. Tujuan untuk mengundang masyarakat, tokoh agama, dan pejabat setempat dengan misi untuk memperkenalkan ajaran dan budaya agama Baha'i merupakan salah satu yang membuktikan asumsi commonalities ini. 
Fase kedua, umat Baha’i menggunakan orientasi assertive accomodation. Assertive accomodation merupakan orientasi yang satu level diatas non assertive accomodation, lebih tegas dan lebih menyuguhkan budaya mereka meskipun sebagai budaya yang terwakilkan. Dimana kelompok dominan (masyarakat setempat) mulai setuju untuk menerima budaya kelompok co culture. Peneliti menemukan bahwa orientasi assertive accomodation ditunjukkan pada kepercayaan masyarakat kepada umat Baha'i yaitu terbukanya interaksi pribadi antara umat Baha'i selaku kelompok co culture dengan masyarakat setempat menjadi bukti bahwa ada penerimaan dan rasa ingin tahu dari masyarakat yang merupakan representasi budaya dominan.

\section{Kesimpulan}

Berdasarkan hasil dari penelitian tentang "Strategi Komunikasi Penganut Agama Baha’i Dalam Membangun Citra Positif di Masyarakat, dapat ditarik kesimpulan bahwa agama Baha'i memiliki ajaran yang humanis. Ajaran yang lebih menitik beratkan kepada kemanusiaan ini mengajarkan kepada umatnya bagaimana menjadi manusia seutuhnya, bagaimana memperlakukan manusia lain dengan baik tanpa melihat latar belakang ras, suku, strata sosial dan lain sebagainya. Hasil penelitian berdasarkan Teori Budaya Pendamping (Co Cultural Theory) menunjukkan bahwa umat Baha'i di desa Cebolek menggunakan strategi Akomodasi untuk membangun citra positif di masyarakat. Strategi ini berkisar pada Akomodasi NonAsertif dan Akomodasi Asertif.

Komponen strategi komunikasi yang dilakukan oleh umat Baha'i dalam membangun citra positif di masyarakat dalam hal perencanaan pesan yaitu dengan melakukan musyawarah terlebih dahulu dengan Majelis Rohani Setempat (MRS). Kemudian pendekatan komunikasi yang dilakukan dengan bersilaturahmi dengan masyarakat sekitar, menggunakan bahasa non verbal seperti memperlihatkan raut wajah yang ramah, memberikan senyuman. Selain itu umat Baha'i menggunakan bahasa verbal seperti menyampaikan informasi mengenai agama Baha’i dengan baik, sopan dan tidak berbelit-belit sehingga pesan atau informasi yang akan disampaikan dapat diterima oleh masyarakat. Terakhir media yang digunakan adalah media cetak seperti brosur dan media elektronik dengan memutar video/film tentang agama Baha’i supaya masyarakat lebih mengetahui tentang agama Baha'i.

\section{Rekomendasi}

Adapun rekomendasi yang dapat peneliti sampaikan yaitu penganut agama Baha’i kedepannya bisa bekerjasama dengan organisasi masyarakat dan pemerintah setempat mengadakan sosialisasi untuk menjelaskan kepada masyarakat tentang agama Baha’i secara mendetail dan diperlukan perencanaan pesan yang lebih matang supaya masyarakat 
Illi Apriliyadi

mengetahui tentang agama Baha'i. Dalam melakukan pendekatan komunikasi, umat Baha’i harus lebih intens berbaur dengan masyarakat sekitar sehingga informasi yang disampaikan mudah dipahami dan dimengerti oleh masyarakat sekitar. Dengan semakin berkembangnya teknologi umat Baha’i di Cebolek tidak hanya menggunakan media brosur atau buletin, namun juga bisa menggunakan media sosial dalam menyampaikan pesan kepada masyarakat. Sehingga terbangun citra positif di lingkungan masyarakat. Peneliti berharap agar kedepannya banyak penelitian lebih lanjut mengenai agama Baha’i dari perspektif ilmu komunikasi seperti negosiasi identitas, pola komunikasi, teknik komunikasi, groupthink maupun kajian lain dari perspektif ilmu komunikasi.

\section{REFERENSI}

Achmad, Nur, dan Nucholis Madjid. Pluralitas agama: kerukunan dalam keragaman. Kompas Media Nusantara, 2001.

Agama Baha’i. Majelis Rohani Nasional Agama Baha’i, 2017.

Agama Baha’i: hasil telaah kasus. Puslitbang, 1985.

Albab, Ananda Ulul. "Interpretasi Dialog Antar Agama Dalam Berbagai Prespektif." Al-Mada: Jurnal Agama, Sosial, Dan Budaya 2, no. 1 (14 Februari 2019): 22-34. https://doi.org/10.31538/almada.v2i1.223.

Amisani, Dewi Haneh. "Konsep kepemimpinan dalam agama baha'i dan persepsinya terhadap pola kepemimpinan negara di Indonesia," 23 Desember 2014. http://repository.uinjkt.ac.id/dspace/handle/123456789/27696.

Arifin, Anwar. Strategi komunikasi sebuah pengantar ringkas. Bandung: Armico, 1982.

Davis, Keith. Management Communication and the Grapevine. Graduate School of Business Administration, Harvard University, 1953.

Effendy, Onong Uchjana. Ilmu komunikasi: teori dan praktek. PT Remaja Rosdakarya, 2011.

Engeström, Yrjo, dan David Middleton. Cognition and Communication at Work. Cambridge University Press, 1998.

Engkus, Kuswarno. Metodelogi Penelitian Komunikasi, Fenomenologi, Konsepsi dan Pedoman. Bandung: Widya Padjadjaran, 2009.

Gudykunst, William B. Theorizing about intercultural communication. Sage, 2005.

Hafied, Cangara. Perencanaan Dan Strategi Komunikasi. Jakarta: Raja Grafindo Persada, 2014. 
Hakim, A. Lukman. "Strategi Komunikasi Lintas Agama FKUB Surabaya Dalam Menangani Konflik." Al-Mada: Jurnal Agama, Sosial, Dan Budaya 1, no. 1 (5 Januari 2018): 19-34. https://doi.org/10.31538/almada.v1i1.129.

Haris, Munawir. "Pencarian Otentisitas Diri Komunitas Mu'allaf Di Kabupaten Sorong Papua Barat.” Al-Qalam 20, no. $2 \quad$ (9 Januari 2016): 329. https://doi.org/10.31969/alq.v20i2.192.

Hartatik, Puji, dan LISTYANINGSIH. "Persepsi Masyarakat terhadap Kelompok Penganut Agama Bahai di Desa Cebolek Kidul Kecamatan Margoyoso Kabupaten Pati.” Kajian Moral dan Kewarganegaraan 7, no. 2 (24 Juni 2019). https://jurnalmahasiswa.unesa.ac.id/index.php/jurnal-pendidikankewarganegaraa/article/view/28252.

Heath, Robert L., dan W. Timothy Coombs. Today's Public Relations: An Introduction. SAGE, 2006.

Hidayat, Samsul. "Stereotip Mahasiswa IAIN Pontianak Terhadap Agama Baha'i." Religió: Jurnal Studi Agama-Agama 7, no. 1 (20 Maret 2017): 55-83. https://doi.org/10.15642/religio.v7i1.703.

Kasali, Rhenald. Manajemen public relations: konsep dan aplikasinya di Indonesia. Pustaka Utama Grafiti, 1994.

Lexy J, Moloeng. Metodologi penelitian Kualitatif. 29 ed. Bandung: Rosdakarya, 2011.

Liliweri, Alo. Strategi Komunikasi Masyarakat. Lkis Pelangi Aksara, 2010.

Littlejohn, Stephen W., dan Karen A. Foss. Theories of Human Communication: Tenth Edition. Waveland Press, 2010.

Moustakas, Clark E. Phenomenological Research Methods. 6. print. Thousand Oaks, Calif.: Sage Publ, 1999.

Nadroh, Siti, dan Syaiful Azmi. Agama-agama Minor. Jakarta: Kencana, 2015.

Nuh, Nuhrison M. “Analisis Kebijakan Pemerintah terhadap Penganut Agama Baha'i di Kabupaten Pati, Provinsi Jawa Tengah.” Harmoni 14, no. 3 (2015): 129.

Orbe, Mark P., dan Tabatha L. Roberts. "Co-Cultural Theorizing: Foundations, Applications \& Extensions." Howard Journal of Communications 23, no. 4 (1 Oktober 2012): 293-311. https://doi.org/10.1080/10646175.2012.722838.

Pace, R. Wayne, Brent D. Peterson, dan M. Dallas Burnett. Techniques for Effective Communication. Addison-Wesley, 1979. 
Illi Apriliyadi

Pamungkas, Alem Joko, dan Hasta Mardi Setiawan. "Strategi Public Relations Dalam Membangun Citra Positif (studi Empiris Pada Pondok Pesantren Modern Darul Amanah Sukorejo Kabupaten Kendal).” Jurnal Egaliter 2, no. 03 (2018).

Panjaitan, Anna Kostantia. "Implikasi Pengosongan Kolom Agama Dalam Kartu Tanda Penduduk Terhadap Pemenuhan Hak Konstitusional Umat Baha'i." Indonesian State Law Review (ISLRev) 1, no. 1 (1 November 2018): 1-16. https://doi.org/10.15294/islrev.v1i1.26936.

Pietkiewicz, Igor, dan Jonathan A. Smith. "A practical guide to using interpretative phenomenological analysis in qualitative research psychology." Psychological journal 20, no. 1 (2014): 7-14.

Rojiati, Umi. "Manajemen Komunikasi Sosial Penganut Agama Baha’i." Communicatus: Jurnal Ilmu Komunikasi 3, no. 1 (25 Juni 2019): 1-16. https://doi.org/10.15575/cjik.v3i1.5033.

Rosyid, Moh. "Memotret Agama Baha’i Di Jawa Tengah Di Tengah Lemahnya Perlindungan Pemda." VIDYA SAMHITA: Jurnal Penelitian Agama 2, no. 2 (8 Desember 2017). http://ejournal.ihdn.ac.id/index.php/vs/article/view/170.

. "Potret Perkawinan Umat Agama Baha'i Dengan Uu Nomor 1 Tahun 1974: Studi Kasus Di Pati Jawa Tengah.” YUDISLA : Jurnal Pemikiran Hukum Dan Hukum Islam 7, no. 2 (2016): 435-69. https://doi.org/10.21043/yudisia.v7i2.2163.

—. "Resolusi Konflik Umat Agama Baha'i Dengan Muslim: Studi Kasus Di Pati Jawa Tengah." Harmoni 18, no. 1 (30 Juni 2019): 424-42. https://doi.org/10.32488/harmoni.v18i1.345.

Ruslan, Rosady. Manajemen humas dan manajemen komunikasi: konsepsi dan aplikasi. Revisi. Jakarta: PT Raja Grafindo Persada, 2002.

Senin, Nurhanisah, dan Khadijah Mohd Khambali. "Islamic View on the Concept of Unity of Religion In.” International Journal of Humanities, Philosophy, Language 1, no. 4 (2018): 11.

Smith, Jonathan A., Paul Flowers, dan Michael Larkin. Interpretative Phenomenological Analysis: Theory, Method and Research. SAGE, 2009.

Sulistyani,. Wawancara dengan Ibu Sulistyani, bendahara MRS Agama Baha’i Pati, 2020.

Vries, Jelle de. "Jamal Effendi and Sayyid Mustafa Rumi in Celebes: The Context of Early Baha’i Missionary Activity in Indonesia." Baba'i Studies Review 14, no. 1 (1 Desember 2007): 23-37. https://doi.org/10.1386/bsr.14.23_1.

Wawancara dengan Penganut Agama Bahai, Maret 2020. 